\title{
Head Ultrasound in Neonatal Hypoxic-Ischemic Injury and Its Mimickers for Clinicians: A Review of the Patterns of Injury and the Evolution of Findings Over Time
}

\author{
Jacqueline Salas ${ }^{\mathrm{a}, \mathrm{b}} \quad$ Aylin Tekes $^{\mathrm{b}, \mathrm{c}}$ Misun Hwang ${ }^{\mathrm{b}, \mathrm{d}}$ Frances J. Northington ${ }^{\mathrm{a}, \mathrm{b}}$ \\ Thierry A.G.M. Huisman ${ }^{b, c}$ \\ a Division of Neonatology, Department of Pediatrics, Johns Hopkins University School of Medicine, Baltimore, MD, \\ USA; ${ }^{b}$ Neurosciences-Intensive Care Nursery Group, Johns Hopkins University School of Medicine, Baltimore, MD, \\ USA; 'Section of Pediatric Neuroradiology, Division of Pediatric Radiology, Russell Morgan Department of Radiology \\ and Radiological Science, Johns Hopkins University School of Medicine, Baltimore, MD, USA; d Division of Pediatric \\ Radiology, Russell Morgan Department of Radiology and Radiological Science, Johns Hopkins University School of \\ Medicine, Baltimore, MD, USA
}

\section{Keywords}

Hypoxic-ischemic encephalopathy · Birth asphyxia · Brain injury · Neonatal development

\footnotetext{
Abstract

Hypoxic-ischemic injury (HII) of the neonatal brain and resulting clinical hypoxic-ischemic encephalopathy remains a significant cause of morbidity and mortality in the neonatal population. Ultrasound (US) has emerged as a powerful screening tool for evaluation of a neonate with suspected HII. The pattern of injury on brain imaging has crucial implications in therapies and predicted neurodevelopmental outcomes. US has become increasingly effective at determining the pattern, timing, and extent of injury in $\mathrm{HIl}$ as well as differentiating these findings from a host of diagnoses that can result in a similarly appearing clinical picture. Repeated US studies over a patient's course can define the evo-
}

() 2018 S. Karger AG, Basel

E-Mail karger@karger.com www.karger.com/neo lution of findings from the acute through chronic phase in addition to identifying any complications of therapy. US also has the added benefits of easy portability, no need for patient sedation, and a relatively low cost when compared to other imaging modalities like magnetic resonance imaging (MRI). It is crucial that clinicians understand the full capabilities of advanced US in identifying an underlying diagnosis, directing appropriate therapy, monitoring disease progress, and finally in predicting outcomes, thus improving the care of neonates with encephalopathy. The following article demonstrates the breadth of uses for US in the full-term neonate with encephalopathy, its limitations, the patterns of injury seen, and their evolution over time. We will also briefly review several clinical mimickers of HII for comparison.

ㄷ) 2018 S. Karger AG, Basel

We dedicate this work to the memory of Dr. Andrea Poretti.
Jacqueline Salas, MD

Division of Neonatology, Johns Hopkins University School of Medicine The Charlotte R. Bloomberg Children's Center, 1800 Orleans St. Baltimore, MD 21287 (USA)

E-Mail jpipino1@jhmi.edu 
Fig. 1. Normal head ultrasound of a fullterm neonate 1 day after birth. Coronal view through the anterior fontanelle (a) demonstrating a normal configuration of the bodies of the lateral ventricles (arrows). The lateral ventricles may appear somewhat small on the initial head ultrasound in the term neonates. Note the normal echogenicity of the brain parenchyma: in the full-term neonate, gray and white matter echogenicities blend in without distinctive discrimination. b Sagittal view through the anterior fontanelle demonstrating the midline structures. Normal corpus callosum (arrow) and thalamus (star). The belly of the pons (thick arrow) and the vermis (line) demonstrate normal hyperechogenicity. Parasagittal view (c) through the anterior fontanelle demonstrating the caudothalamic notch (arrow), the most common location for residual germinal matrix. The arrowhead points to the caudate head and the star denotes the thalamus. Coronal view through the mastoid fontanelle (d) showing the cerebellar hemispheres with the highest detail as the probe is closest to the posterior fossa on this view. The cerebellar vermis is in the middle with a relatively high echogenicity. Cerebral peduncles can be seen in the midline immediately above the vermis (arrows).
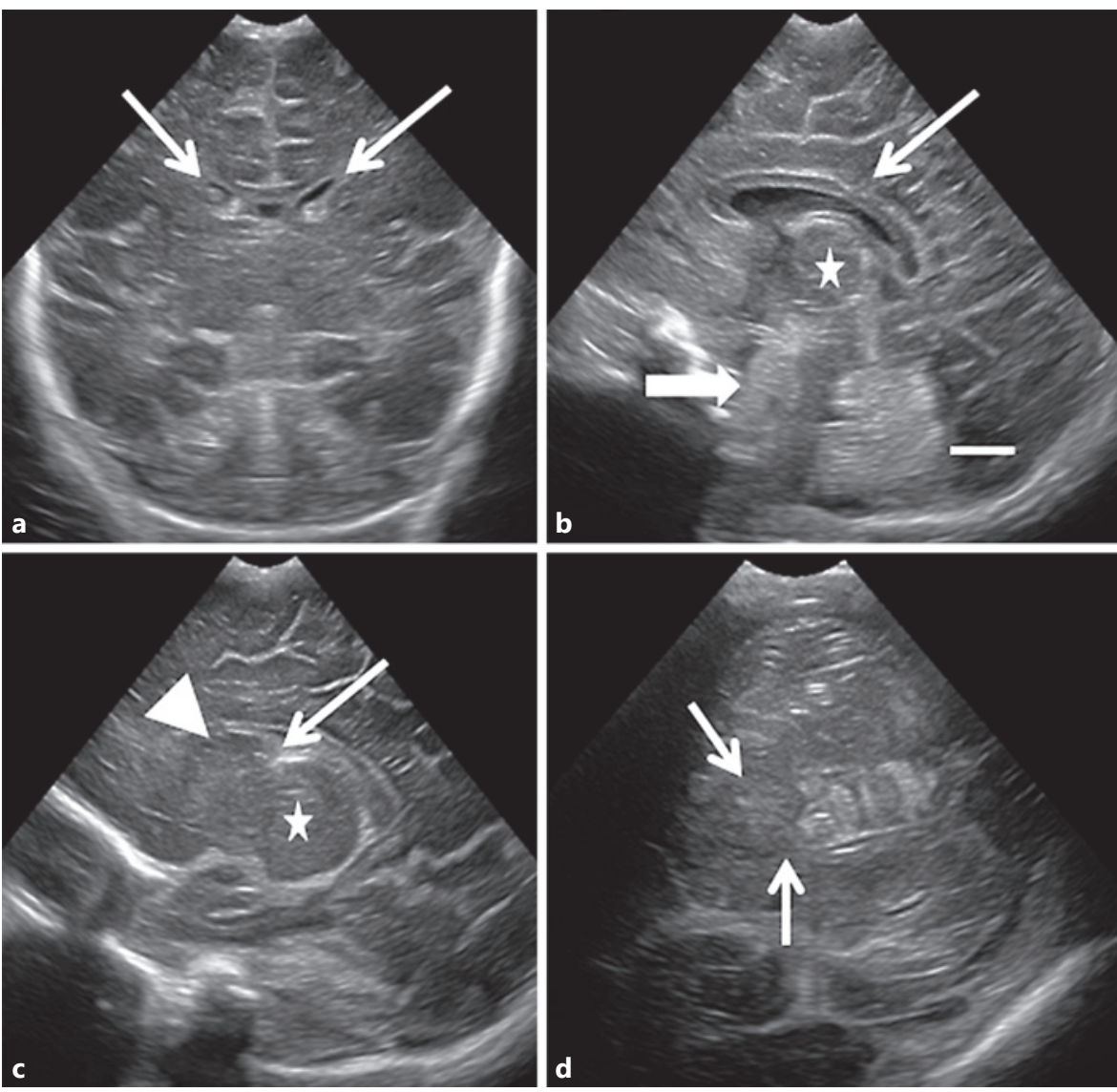

\section{Ultrasonography in Hypoxic-Ischemic Injury}

Hypoxic-ischemic injury (HII) of the neonatal brain and subsequent clinical hypoxic-ischemic encephalopathy (HIE) affects 1-3 per 1,000 live births in developed countries and is responsible for a significant burden of morbidity and mortality in the pediatric population [1]. Different imaging modalities, including ultrasound (US) and magnetic resonance imaging (MRI), have been used to classify patterns of cerebral injury within the realm of HIE-related injury. Correct classification of injury informs treatment options, allows monitoring of treatment progress, and often predicts motor and neurocognitive outcomes. MRI is predictive of long-term outcomes in patients with HII/HIE in multiple studies [2-5]. However, MRI is costly, lacks portability, is time consuming, and, consequently, is limited in its utility in nonacademic centers, in low-income countries, and with critically ill patients who are too unstable to be moved. Brain US has emerged as a powerful, inexpensive adjunctive and alternative tool to MRI. US is widely available, can be per- formed bedside without sedation, can be repeated as often as necessary, has no side effects, and, when performed by an experienced sonographer using high-end equipment, provides a wealth of anatomical and functional information. Figure 1 is an example of a normal head US of a neonate born at term. It demonstrates the high level of detail that can be achieved with US.

The use of multiple acoustic windows and variablefrequency US transducers has greatly improved the diagnostic sensitivity and specificity of US [6]. Variable-frequency transducers allow the sonographer to focus on near-, mid-, and far-field pathologies. Many lesions such as subdural hematomas or deep gray matter abnormalities once poorly visualized by US are now more readily apparent [7]. With optimal technique and view, US can delineate multiple focal intracranial pathologies such as intracranial hemorrhages, calcifications, ischemia, and brain abscesses. In addition, a wide array of developmental disorders such as Chiari and Dandy Walker malformations and corpus callosum agenesis/dysgenesis, as well as vascular anomalies such as vein of Galen aneurysmal 
malformation, ventriculomegaly, and migrational abnormalities can also be revealed [8]. Detection of posterior fossa pathologies has been greatly enhanced by the addition of posterior and mastoid fontanel views to the standard anterior fontanel approach $[9,10]$.

Cranial US has many roles in evaluating patients when there is a concern for neonatal HII. US findings evolve over time just as the injury itself does [11]. Thus, specific patterns of injury and focal findings can provide important clues as to the severity and duration of the injury [12]. By repeating studies over time, one can see the full evolution of the disease process from the acute to the chronic phase $[13,14]$. Once the pattern of brain injury is detected, it can help determine prognosis [13]. Focal findings on US can sometimes explain specific clinical presentations, such as the presence of unilateral seizures in the setting of a focal arterial stroke. US detection of stroke is improving but remains less sensitive when compared to MRI [15]. In addition, US is a quick and easy tool which can be used to assess the patient during an acute clinical deterioration, allowing the practitioner to implement appropriate therapies more rapidly [14]. Importantly, US can also redirect the diagnostic workup if findings are not consistent with HII [16]. There are several mimickers of HIE and having a fast screening tool available at bedside to guide diagnosis and decision-making is helpful.

\section{Therapeutic Hypothermia and Imaging}

Therapeutic hypothermia (TH) is currently the only therapy for infants with moderate to severe encephalopathy due to HII. TH has been shown to improve neurodevelopmental outcomes and reduce the severity of imaging findings on MRI $[17,18]$.

Other than a reduction in neuropathology due to presumptive limitation/improvement of the brain injury, it is not yet fully understood how $\mathrm{TH}$ affects imaging findings, in particular conventional and diffusion MR imaging findings. There is some evidence that it delays the conspicuity of MRI changes. For example, the appearance and evolution of diffusion-weighted imaging findings, in particular the so-called pseudo-normalization of diffusion restriction, is delayed for several days following TH [19]. Given the that a proposed neuroprotective mechanism of injury of $\mathrm{TH}$ is a reduction in secondary injury, there is a biologic basis for a delay in imaging changes which has been observed clinically. Others have found no difference in MRI findings during or after hypothermia [20]. The prognostic value of MRI does not appear to be affected by TH [21].
US can be performed at or before the initiation of $\mathrm{TH}$ to evaluate for the presence of established injury from an insult prior to the time of delivery or from a particularly severe perinatal event. Importantly, pretreatment US should evaluate for brain pathology that clinically mimics HIE or pathology that would be a relative contraindication to TH such as focal hemorrhage, focal arterial stroke, metabolic diseases, infections, or brain malformations. These are all relative contraindications because $\mathrm{TH}$ has been used in focal arterial stroke and is being considered as treatment for some metabolic diseases [22, 23]. Caution must be taken because US imaging does not provide optimal information in some of these diseases [15]. Correlation with clinical status must always be considered. US is usually repeated on completion of the TH to assess persistence of initial indicators of injury or appearance of new findings. During TH, US can be used to quickly detect abnormalities such as an acute hemorrhage when there is a significant clinical change.

\section{Doppler Ultrasonography and Resistive Indices}

Duplex US with spectral analysis of the blood flow curves during systole and diastole allows calculation of the resistive index (RI). It provides a measurement of cerebral vascular dynamics and the integrity of cerebral autoregulation. Abnormalities in RI have been correlated with prognosis. An abnormal RI (equal to or less than 0.55), in the first $72 \mathrm{~h}$ after birth, has been found to be highly predictive of a poor prognosis with either death or severe disability [24-28]. Of note, these studies were performed in the pre-TH era. In a study performed in 2011 [29], the positive predictive value of a low RI value for a poor outcome decreased from approximately $84 \%$ for patients who did not undergo hypothermia therapy to only $60 \%$ in those who did. A normal RI in the early phase of injury (within the first 6-12 h) can be deceiving as these patients can still develop significant disability or death $[24,25]$. This may be due to the confounding effect of increased intracranial pressure, patent ductus arteriosus, or cardiac dysfunction. If an RI is performed early enough after admission and before or simultaneous with the onset of TH, a low RI value may retain some of its prognostic value [30]. Its predictive value returns once the infant is rewarmed [31]. The reason for a loss of the predictive value of a low RI during TH is not well understood. Hypotheses include a relative vasoconstriction in the cerebral circulation or changes in metabolic demands with $\mathrm{TH}[29,32,33]$. 

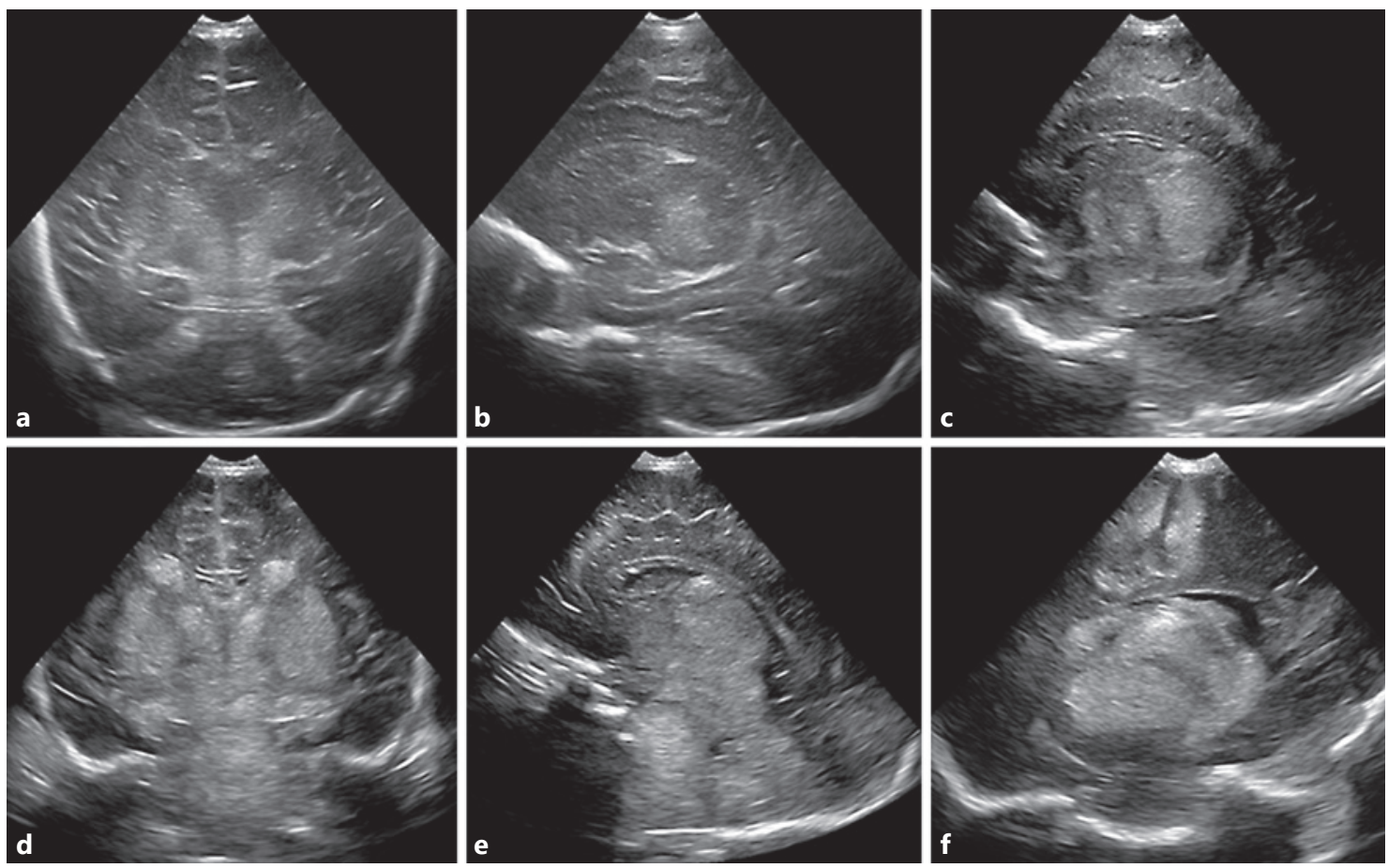

Fig. 2. Central pattern of injury. Full-term neonate with complete placental abruption. Coronal $(\mathbf{a})$ and parasagittal $(\mathbf{b}, \mathbf{c})$ images through the anterior fontanelle. a, b Images were obtained $2.5 \mathrm{~h}$ after birth. Note the bilateral symmetric increased echogenicity in thalami extending into the cerebral peduncles representing ischemic injury. Ventricles are slit-like due to edema from the central structures. Follow-up head ultrasound within 48 h on (c-f) demonstrate interval evolution/maturation of ischemia, now settled in the entire basal ganglia and thalami again in a bilateral symmetric fashion (d, e). Some echogenicity may be due to hemorrhage following reperfusion injury in addition to ischemia. Note the hyperechogenicity in the perirolandic region in $\mathbf{f}$. This infant died 3 days after birth.

\section{Evolution and Pattern of Injury in HII}

\section{Acute Phase}

The acute phase of HII begins when the injury occurs and continues for 6 to $15 \mathrm{~h}$ [34]. It is characterized by primary neuronal cell death due to hypoxia-ischemia, with contributions from oxidative stress, excitotoxicity, and inflammation [35]. This leads to additional cell death and the development of cerebral edema initially $[15,16,35]$. Secondary energy failure propagates the initial injury, causing further damage of brain tissue [34].

Cerebral edema takes time to develop and can be very mild in the early stages. Accordingly, US findings can be negative for $24-48 \mathrm{~h}$ following the insult. It should also be noted that in some cases the insult may be remote from the time of delivery and so edema may have already developed and resolved by the time of birth. Findings typically become apparent on US after $24-48 \mathrm{~h}$ after HII, with some variability dependent on the severity of the injury and the presence of coexistent complications [11, $25,36]$. White matter edema is demonstrated on US by enhanced gray-white matter differentiation. The echogenicity of the white matter increases in relation to the less echogenic, more compact cortical gray matter [37]. An elevated quantitative ratio of white to gray matter echogenicity has been associated with HII and with markers of white matter injury on DTI [30, unpubl data]. Other indicators of parenchymal edema include effacement of the cerebral sulci, compressed slit-like ventricles, and narrowing of the intrahemispheric fissure and basal cisterns. It is important to note that ventricles may be small in the first $36 \mathrm{~h}$ after birth in neonates without injury or with edema so care must be taken in the interpretation of this finding [38]. Edema is observed in Figures 2-4 along with additional findings corresponding to individual patterns of injury. Duplex sonography typically shows decreased RI values, i.e., less than 0.60 with significant edema. 

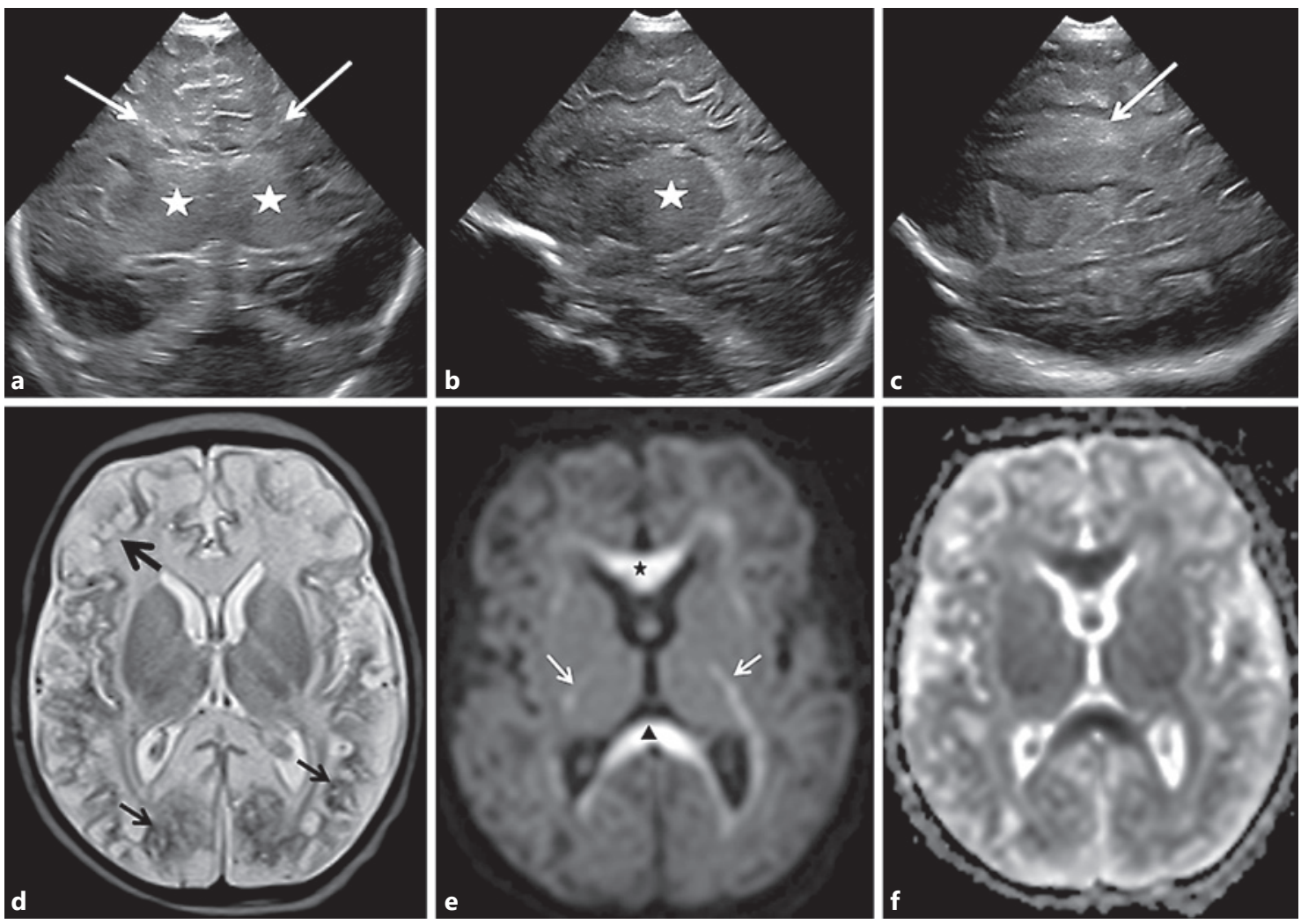

Fig. 3. Near total gray and white matter injury in a full-term neonate. Head ultrasound performed $17 \mathrm{~h}$ after birth in a full-term neonate with severe hypoxic-ischemic encephalopathy. Edema is represented by the relatively high signal throughout the white matter in comparison to the marked low signal of the cortex, best appreciated in the cingulate gyrus region (long arrows). Note slit-like ventricles (a) due to diffuse brain edema. Resistive index values in the anterior cerebral artery were also decreased at $0.34-0.4$ in this patient (not shown), another indication of this edema. Also note the high echogenicity of the thalami bilaterally best noted in a

\section{Subacute Phase}

With the evolution of primary and secondary injury over a few days after birth, the injury advances into the subacute stage. In term infants, subacute injury is marked by progressive demarcation of central gray matter and white matter injury/edema. Four distinct patterns of injury can emerge based on the type and duration of HII. Myers [39] described the most widely utilized system in the current literature. The presence of multiple patterns of injury (and multiple different classification systems) likely reflects the complexities of human brain injury and differences in timing, insult type, and severity in various clinical scenarios. For the purpose of this review the Myers classification will be used. (stars). MRI of the brain performed on day of life 10. The axial T2weighted image (d) demonstrates generalized parenchymal volume loss. The dark T2 signal along the cortex indicates cortical laminar necrosis (thin arrows). Note the cystic changes in the subcortical white matter (thick arrow). Generalized high T2 signal of the white matter and thalami reflecting edema. Diffusion tracer image (e) and apparent diffusion coefficient map (f) demonstrating restricted diffusion in the genu (star) and splenium (arrowhead) of the corpus callosum and internal capsules bilaterally (arrows) reflecting wallerian degeneration.

\section{Near Total Asphyxia}

Placental abruption or cord prolapse are typical precipitants to the severe compromise in fetal blood flow that is seen with near complete asphyxia. The brain regions most vulnerable to near total asphyxia are the basal ganglia, the thalamus sparing the internal capsule, the brainstem, and the cerebellum $[40,41]$. This type of injury is characterized by extensive gray and white matter regions of hyperechogenicity on US and it is commonly described as a central pattern of injury (Fig. 2). It is common to observe a hyperechoic putamen or thalamic structure juxtaposed to a relatively less echogenic internal capsule [42]. These findings can be bilateral, unilateral, or focal. Typically, findings become more pronounced after the first 24-48 h before which time US can appear negative. 

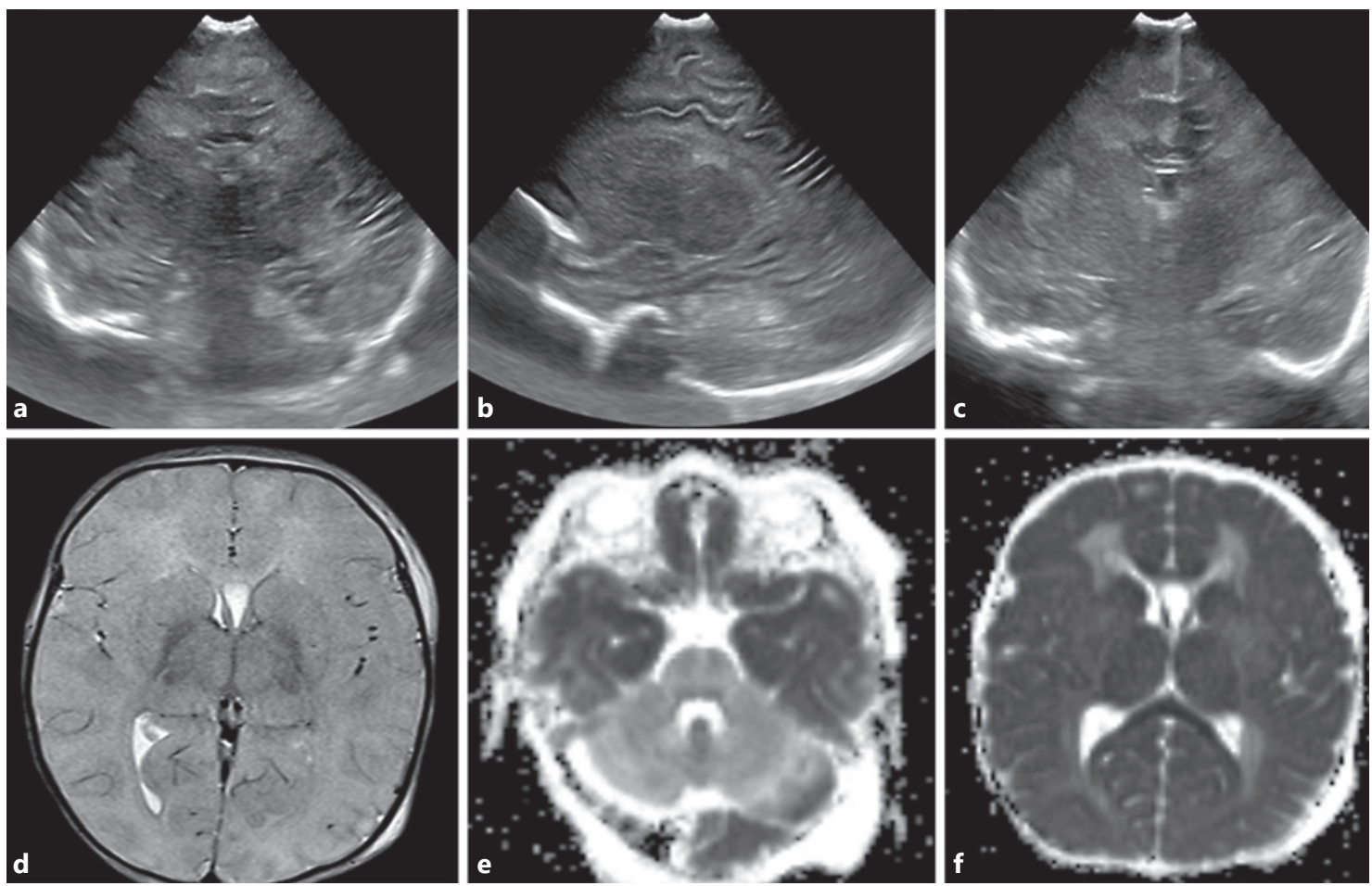

Fig. 4. Near total white and gray matter injury in a full-term neonate. Head ultrasound images through the anterior fontanelle on coronal (a, c) and parasagittal (b) planes within the first $24 \mathrm{~h}$ after birth. The "swollen" appearance of the supratentorial brain is due to bilateral symmetric and significant cytotoxic edema affecting the white matter. There is marked differentiation between gray matter and white matter, well seen throughout the entire brain both in anterior and posterior distributions. The increased echogenicity of the basal ganglia and thalami with poor distinction of their borders again reflect edema. On magnetic resonance images obtained 4 days after birth, the T2-weighted image (d) shows a diffuse increased signal of the white matter, cortex, basal ganglia, and thalami with poor gray-white matter differentiation. Apparent diffusion coefficient maps (e, f) reveal diffuse supratentorial restricted diffusion (diffusion trace image not shown). The diffuse symmetric parenchymal injury of the supratentorial brain in comparison to normal cerebellum, as seen in e, is critical in identifying this injury. This is also known as the white cerebellar sign.
On average, infants with near total asphyxia have a higher risk of death when findings are severe compared to those with watershed injuries. If they survive, children with this type of injury have a significant risk of cognitive and motor impairment $[2,42,43]$. In particularly severe cases, brainstem involvement is an independent risk factor for death in the neonatal period $[44,45]$.

\section{Watershed Injury}

Watershed injury typically occurs following partial prolonged asphyxia with a concurrent hypoxic acidotic state $[39,46]$. Hypoperfusion to the cortex occurs at the periphery of major arterial perfusion territories [47, 48]. This can become apparent on head US in several ways. It typically manifests as a wedge-shaped region of hyperechogenicity at border zones. Border zones occur in the frontal lobe, near the posterior horn, in the parafalcine region in the subcortical white matter, and in the parieto-occipital region. Cortical injury may also appear as general peripheral edema. Compared to the near complete asphyxia, patients with border zone injury tend to have milder clinical signs and less severe outcomes [2]. However, cerebral palsy is observed in this patient population when focal gyral atrophy occurs on US [42]. MRI is generally superior to US at detecting this type of injury $[42]$.

\section{Primary White Matter Injury}

Primary white matter injury occurs with a history of partial asphyxia in the setting of sustained hypoxia [39]. The classic US finding is subcortical and periventricular white matter hyperechogenicity underlying the relatively dark cerebral cortex, resulting in increased cortico-medullary differentiation on US [42]. 
In term infants, this type of injury, particularly in patients with internal capsule involvement, commonly precedes global developmental delay, visual impairment, and seizures [3]. However, this must be correlated to clinical findings when diagnosed with US as outcomes can be variable [42].

Concurrent Partial and Near Total Asphyxia

The basal ganglia is the primarily affected area, typically manifesting as bilateral hyperechogenicity on US [39]. Watershed cortical involvement, focal infarctions, or global injury often accompany the basal ganglia findings [42] (Fig. 3, 4). The combination of partial and total asphyxia is associated with more ominous outcomes than other patterns of injury. Bilateral involvement and a higher intensity of the echogenicity predict poorer neurodevelopmental and mortality outcomes in the short term, as well as worse cognitive and motor outcomes in the long term, than less extensive injuries $[4,5]$.

\section{Chronic Phase}

The chronic phase of the injury occurs weeks after the initial insult. Necrosis of the affected areas evolves into scarring of the initial injury sites. This often produces generalized atrophy of these regions in severe cases. Progressive volume loss of the central gray matter is most typically seen in term neonates. White matter volume loss is also possible and may result in an ex-vacuo ventriculomegaly, sometimes accompanied by widening of the subarachnoid space and microcephaly in the chronic phase.

\section{Other Possible Findings}

\section{Cerebellar Involvement}

Injury to the cerebellum was not a well-defined aspect of Myers' original classification; however, it deserves note. Abnormalities including focal hyperechogenicity require posterior and mastoid fontanel views to be performed. Injury in this region most often occurs with severe HII and has significant developmental implications $[49,50]$.

\section{Normal US}

It is important to note that infants with HII/HIE may have normal appearing anatomical US/MRI findings on follow-up. The lack of findings on imaging does not preclude the risk of developmental delay [51]. Detection of abnormalities may be improved by advanced imaging techniques as discussed later [52].

\section{Potential Complications}

In addition to the primary and secondary mechanisms of injury, several complications can worsen the disease process; however, they are rare in this population. Intracranial hemorrhage, including a choroid plexus bleed, a more profound intraventricular hemorrhage or, intraparenchymal hemorrhage, can occur at the time of initial injury. It can also occur with reperfusion after the primary episode of ischemia or with venous thrombosis [53, 54]. Acute hemorrhages present as hyperechogenic focal lesions that may become iso- and later hypoechogenic on follow-up during involution.

\section{Mimics}

There are several conditions that can present with neonatal encephalopathy and mimic HIE. US can reveal characteristic findings of these conditions to redirect a provider to the appropriate therapy. The following are a few common mimickers of HIE whose imaging patterns can be identified on US.

\section{Hypoglycemia}

Neonates with severe symptomatic hypoglycemia can have neurologic signs that mimic HIE. Cranial US in this setting typically reveals hyperechogenicity of posterior subcortical white matter and overlying cortex with sparing of the central gray matter. Detection is improved with posterior fontanel views. However, these findings are not specific and are not consistently observed on US despite the use of posterior fontanelle views. MRI should be performed to confirm suspected hypoglycemic brain injury. Severe hypoglycemia can also occur concurrently with HIE, producing a mixed pattern of injury.

\section{Neonatal Stroke}

Stroke can present with seizures, hypotonia, lethargy, and poor feeding, all of which could be mistaken for signs of HIE. Cranial US may initially only reveal a slight hyperechogenicity of the cortex and white matter in a vascular distribution, most commonly the middle cerebral artery territory [55]. Hyperechogenicity in the peripheral cerebral hemispheres, the basal ganglia, and the thalamus are all common findings. Sonographic abnormalities become more defined as the stroke evolves [15]. The focal nature of the lesion is key to diagnosis (Fig. 5). It is important to note that stroke and HIE can occur together in rare instances. 
Fig. 5. Arterial stroke in a full-term neonate. Parasagittal image obtained 3 days after birth through the anterior fontanelle demonstrating a focal peripheral hyperechogenicity involving the cortex and subcortical white matter in the left parietal lobe representing a unifocal stroke (a). Note the high signal in the diffusion tracer image obtained 6 days after birth (corresponding apparent diffusion coefficient map not shown) secondary to restricted diffusion (b).
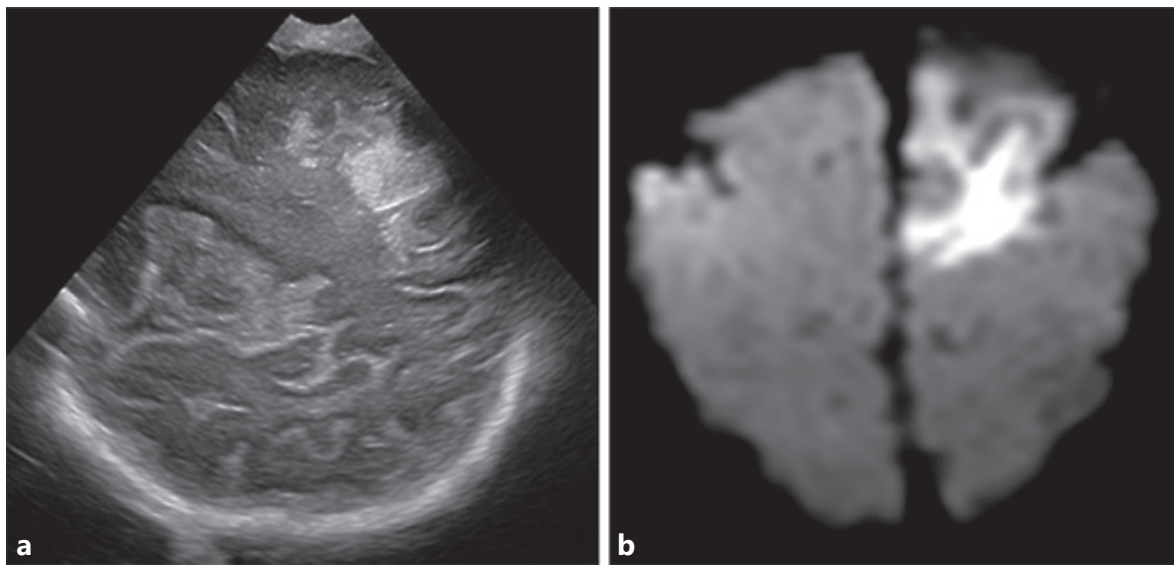

\section{Infections}

Meningitis with or without concurrent brain abscesses can present with an ill-appearing, lethargic, and hypotonic neonate possibly with simultaneous seizure activity. The most common US findings are a widening of the subarachnoid and subdural space, hyperechogenic pia mater, prominent subarachnoid vessels, layering debris within the subarachnoid space, and hyperperfusion of the meninges on power Doppler sonography. On follow-up, ventriculomegaly may result with adhesions/webs within the ventricles. Circular hyperemic foci scattered within the brain parenchyma can represent developing brain abscesses. Bacterial meningitis can present with cerebral infarctions secondary to an arterial vasculitis or thrombophlebitis [56].

\section{Metabolic Diseases}

Urea cycle disorders, nonketotic hyperglycinemia, and others can imitate HIE in symptomatology. Imaging findings of neonates with metabolic diseases can range from changes in white matter volume and echogenicity to cysts, calcifications, and structural abnormalities [16]. The following are specific examples.

\section{Sulfite Oxidase Deficiency}

Indications of sulfite oxidase deficiency on US include large cystic structures in the white matter, possible hypoplasia of the corpus callosum, and ventriculomegaly. Basal ganglia involvement is possible and may mimic certain patterns of HIE [57-59].

\section{Molybdenum Cofactor Deficiency}

Molybdenum cofactor deficiency frequently shows initial US findings of diffuse increased echogenicity and then subsequent parenchymal hyperechogenicity and calcifications in the basal ganglia, white matter cysts, and later cerebral atrophy [60].

\section{Zellweger Syndrome}

Zellweger syndrome, a peroxisomal disorder with migrational abnormalities, can show subependymal cysts, ventricular enlargement, lenticulostriate vasculopathy, and gyral malformations on US. Though symptomatically similar, neonates with Zellweger syndrome are more easily differentiated from neonates with HII based on imaging findings $[16,61,62]$.

\section{Nonketotic Hyperglycinemia}

US commonly shows hypoplasia of the corpus callosum in neonates with nonketotic hyperglycinemia $[63,64]$.

\section{Maple Syrup Urine Disease}

In maple syrup urine disease, edema, white matter hyperechogenicity, and central gray matter hyperechogenicity can be observed (Fig. 6), with corresponding white matter tract disease apparent on MRI. Neonates with maple syrup urine disease are frequently not symptomatic until 4-7 days after birth [65].

\section{Reliability and Predictive Value of US Findings}

US has value as a screening tool in infants with HIE as outlined above; however, it is not uncommon that significant abnormalities are not detected until 24-96 h after birth $[11,25,36]$. Thus HII may not be immediately apparent and the predictive value of a normal head US in this early phase is low. If there is a significant abnormal- 
Fig. 6. Maple syrup urine disease. Full-term neonate who presented with poor feeding and lethargy at 6 days of life. Head ultrasound performed 16 days after birth. Coronal ultrasound (a) and sagittal ultrasound (b) through the anterior fontanelle revealing normal echogenicity of the white matter with a subtle increased echogenicity of the thalami. Brain magnetic resonance imaging was performed 20 days after birth. The axial T2-weighted image shows global white matter hyperintensity in the supratentorial brain involving the posterior limb of the internal capsules with a normal cortical signal. The diffusion tracer image $(\mathbf{d})$ on the coronal plane mirrors these findings, with densely restricted diffusion in corticospinal tracts that extends from the bilateral internal capsule into the cerebellar tracts and brainstem (apparent diffusion coefficient map not shown).
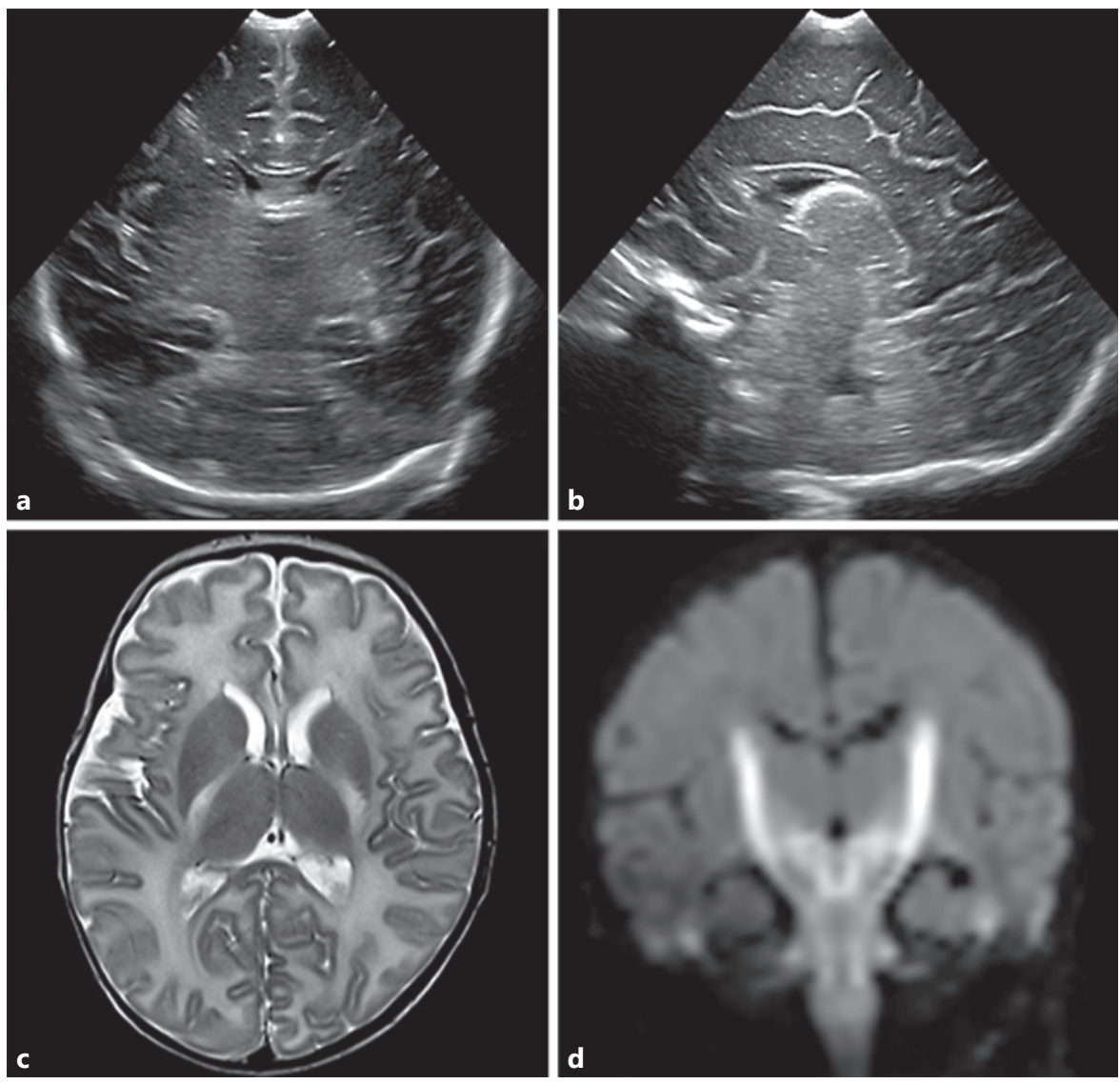

ity already present at this stage (less than $24 \mathrm{~h}$ after birth), it is highly predictive of a poor outcome due to a particularly severe insult or because the injury occurred prior to the onset of labor [13].

Rutherford et al. [43] demonstrated that basal ganglia and thalamic changes are more likely to be visualized on MRI than US. Those infants who do have abnormalities on US develop significant motor deficits, particularly if abnormalities are also seen on MRI [43]. Infarcts and lesions at the convexity of the brain require a linear highresolution probe (14-16 MHz) for evaluation on US. Lesions in the cortex are much less likely to be seen on US compared to MRI [43]. In comparison to autopsy findings, when US is performed less than $12 \mathrm{~h}$ before death, the sensitivity and specificity for thalamic lesions is 100 and $83 \%$, respectively, and for lesions in the cortex it is 76.9 and $100 \%$, respectively [36].

Many of the early studies particularly comparing US to MRI in neonates were performed with less sophisticated transducers and techniques than available today, likely inhibiting their ability to identify subtle findings
[6]. There were also frequent comparisons of early US to MRI done several days later. The injury typically becomes more apparent with time, partially explaining why MRI appears to be more diagnostic than US $[66,67]$. High-end US done concurrently with MRI has 95\% diagnostic accuracy compared to MRI [68].

In more recent studies, there is an improved correlation [13]; however, US and MRI are still not identical in their detection capabilities and their ability to determine the extent of lesions. There is only a slight difference in the positive predictive value for adverse outcomes between head US and MRI findings. However, normal or mildly abnormal findings were not strong prognostic factors for a good outcome, either in US or in MRI [13]. This reaffirms that early imaging is helpful for prognosis if significantly abnormal both in HUS and in MRI; however, normal findings are not definitive predictors of a favorable outcome. US performed a median of 2 days before MRI (the mean age at MRI was 5.4 days) was predictive of a favorable prognosis when the US was normal or had echogenic changes only in the cortex. Deep gray matter chang- 
es on US had a positive predictive value of $67 \%$ and a negative predictive value of $100 \%$ for an adverse outcome. However, MRI remains more reliable in its identification of the extent of injury and association with outcomes [69]. MRI is the gold standard for determining the presence and extent of hypoxic-ischemic brain lesions; even so, additional quantitative imaging modalities are needed to improve the prediction of outcomes, especially in infants who have normal imaging on conventional sequences.

Diffusion-weighted MRI is utilized in HIE to detect injury in the early phase when it may not be apparent on other imaging, to quantitatively correlate brain injury with outcomes, and to more accurately differentiate mimickers such as ischemic injures of other etiology like metabolic diseases and stroke [52, 70-72]. T1/T2 signal abnormalities may not be present or may be very subtle in the first $48 \mathrm{~h}$ after birth; however, apparent diffusion coefficient values are significantly lower than normal in the injured neonatal brain even within the first $48 \mathrm{~h}$ after birth $[67,73]$. Diffusion abnormalities tend to evolve over time, starting as more localized findings in the first $48 \mathrm{~h}$, becoming more diffuse and apparent by day 4-5, and then pseudo-normalizing about 7 days after birth. Infants treated with TH demonstrate more delayed pseudo-normalization around 8-10 days after birth $[67,74]$. Apparent diffusion coefficient values have also been correlated with favorable or unfavorable outcomes [69, 75-77]. Proton MR spectroscopy has emerged as an adjunct imaging modality superior in its ability to detect the full extent of injury in the first $24 \mathrm{~h}$. In particular, lactate to $\mathrm{N}$-acetylaspartate ratios have been correlated with long-term prognosis $[73,75,76$, 78-80]. Arterial spin labeling noninvasively assesses cerebral blood flow by inverting arterial hydrogen protons and has recently been used more frequently in the pediatric population $[81,82]$. Studies have used arterial spin labeling to characterize the timeline and pattern of changes in cerebral blood flow in neonates with HIE $[83,84]$; arterial spin labeling perfusion values, particularly in the basal ganglia and thalamus, correlate with outcomes, especially when combined with MR spectroscopy information [85]. All of these additional modalities have the capability to enhance the power of imaging findings to reliably determine the severity of injury and predict outcomes.

\section{Advances in Ultrasonography Techniques}

Advanced neurosonography techniques have the potential to enhance the diagnostic sensitivity of conventional grayscale and color Doppler US. Contrast-en- hanced US is a technique in which gas-filled microbubbles smaller than red blood cells create an acoustic impedance mismatch to generate a contrast signal within the intravascular compartment. The technique permits real-time quantification of tissue perfusion, specifically via generation of perfusion kinetics curves from which perfusion parameters including wash-in, time to peak, peak intensity, and area under the curve can be derived. The application of the contrast-enhanced US technique is in the preliminary stages due to off-label use in the neonatal brain, but it is showing promise based on the initial case series on neonatal HII [86]. Dynamic color Doppler sonography permits perfusion quantification of a region of interest without intravenous contrast. The method quantifies tissue perfusion by inferring the amount of blood flow through a specific region of tissue during a cardiac cycle based on the mean perfusion velocity of vessels and the mean perfused area, which then reflects the differences in small vessel perfusion between systolic and diastolic phases. It has been used recently in HII to quantify reperfusion injury [87].

Elastography is a technique in which tissue stiffness can be quantified based on the perpendicular acoustic waves produced by transient deformation of the tissue by a focused US pulse, and its application in neonatal brain for evaluation of HII is still to be studied [88]. Other perfusion quantification Doppler techniques include ultrafast Doppler, which has the benefit of quickly mapping the vascular dynamics of a large region of interest rapidly [89]. This may aid in identifying the full extent of injury in HII, but additional studies are needed to delineate the utility of this technique in practice.

\section{Summary}

Cranial US is a valuable screening tool in the diagnosis and management of encephalopathic neonates. In the acute time frame when it can be difficult to obtain more advanced imaging, US is helpful in determining the etiology of encephalopathy, whether it be due to HII or a host of mimickers which would warrant alternative therapies. Through repeated evaluations, it can further identify the pattern, timing, and severity of injury. It has the added benefits of being safe, cost-effective, and portable. Advances in US equipment and techniques have significantly improved its detection abilities. When present, abnormalities on high-quality US have proven helpful in predicting outcomes; therefore, medical decisions should not be postponed due to a lack of MRI imaging when the 
US findings are consistent with the clinical picture. Imaging findings should always be combined with exam, electrophysiological data, and other clinical findings to guide management and prognosis determination. MRI remains the gold standard for evaluation of neonates with HII, stroke, and other mimickers, as US studies can sometimes miss or underestimate pathology. However, providers should understand the evolving capabilities and limita- tions of high-end US in neonatal encephalopathy such that its utility can be optimized particularly in those patients in whom additional imaging is not feasible.

\section{Disclosure Statement}

The authors declare no conflict of interests.

\section{References}

1 Kurinczuk JJ, White-Koning M, Badawi N: Epidemiology of neonatal encephalopathy and hypoxic-ischaemic encephalopathy. Early Hum Dev 2010;86:329-338.

2 Miller SP, Ramaswamy V, Michelson D, Barkovich AJ, Holshouser B, Wycliffe N, Glidden DV, Deming D, Partridge JC, Wu YW, Ashwal S, Ferriero DM: Patterns of brain injury in term neonatal encephalopathy. J Pediatr 2005; 146:453-460.

3 Martinez-Biarge M, Bregant T, Wusthoff CJ, Chew AT, Diez-Sebastian J, Rutherford MA, Cowan FM: White matter and cortical injury in hypoxic-ischemic encephalopathy: antecedent factors and 2-year outcome. J Pediatr 2012;161:799-807.

4 Okereafor A, Allsop J, Counsell SJ, Fitzpatrick J, Azzopardi D, Rutherford MA, Cowan FM: Patterns of brain injury in neonates exposed to perinatal sentinel events. Pediatrics 2008; 121:906-914.

5 van Kooij BJ, van Handel M, Nievelstein RA, Groenendaal F, Jongmans MJ, de Vries LS: Serial MRI and neurodevelopmental outcome in 9- to 10-year-old children with neonatal encephalopathy. J Pediatr 2010;157:221-227. e2.

6 Daneman A, Epelman M, Blaser S, Jarrin JR: Imaging of the brain in full-term neonates: does sonography still play a role? Pediatr Radiol 2006;36:636-646.

7 Dinan D, Daneman A, Guimaraes CV, Chauvin NA, Victoria T, Epelman M: Easily overlooked sonographic findings in the evaluation of neonatal encephalopathy: lessons learned from magnetic resonance imaging. Semin Ultrasound CT MR 2014;35:627-651.

8 Orman G, Benson JE, Kweldam CF, Bosemani T, Tekes A, de Jong MR, Seyfert D, Northington FJ, Poretti A, Huisman TA: Neonatal head ultrasonography today: a powerful imaging tool! J Neuroimaging 2015;25: 31-55.

9 Steggerda SJ, Leijser LM, Wiggers-de Bruine FT, van der Grond J, Walther FJ, van WezelMeijler G: Cerebellar injury in preterm infants: incidence and findings on US and MR images. Radiology 2009;252:190-199.
10 Steggerda SJ, de Bruine FT, Smits-Wintjens VE, Verbon P, Walther FJ, van Wezel-Meijler G: Posterior fossa abnormalities in high-risk term infants: comparison of ultrasound and MRI. Eur Radiol 2015;25:2575-2583.

11 Tann CJ, Nakakeeto M, Hagmann C, Webb EL, Nyombi N, Namiiro F, Harvey-Jones K, Muhumuza A, Burgoine K, Elliott AM, Kurinczuk JJ, Robertson NJ, Cowan FM: Early cranial ultrasound findings among infants with neonatal encephalopathy in Uganda: an observational study. Pediatr Res 2016;80: 190-196.

12 Volpe JJ: Neonatal encephalopathy: an inadequate term for hypoxic-ischemic encephalopathy. Ann Neurol 2012;72:156-166.

13 Leijser LM, Vein AA, Liauw L, Strauss T, Veen S, Wezel-Meijler G: Prediction of shortterm neurological outcome in full-term neonates with hypoxic-ischaemic encephalopathy based on combined use of electroencephalogram and neuro-imaging. Neuropediatrics 2007;38:219-227.

14 van Wezel-Meijler G, Steggerda SJ, Leijser LM: Cranial ultrasonography in neonates: role and limitations. Semin Perinatol 2010;34:28-38.

15 Cowan F, Mercuri E, Groenendaal F, Bassi L, Ricci D, Rutherford M, de Vries L: Does cranial ultrasound imaging identify arterial cerebral infarction in term neonates? Arch Dis Child Fetal Neonatal Ed 2005;90:F252-F256.

16 Leijser LM, de Vries LS, Rutherford MA, Manzur AY, Groenendaal F, de Koning TJ, van der Heide-Jalving M, Cowan FM: Cranial ultrasound in metabolic disorders presenting in the neonatal period: characteristic features and comparison with MR imaging. AJNR Am J Neuroradiol 2007;28:1223-1231.

17 Cheong JL, Coleman L, Hunt RW, Lee KJ, Doyle LW, Inder TE, Jacobs SE: Prognostic utility of magnetic resonance imaging in neonatal hypoxic-ischemic encephalopathy: substudy of a randomized trial. Arch Pediatr Adolesc Med 2012;166:634-640.

18 Azzopardi D, Brocklehurst P, Edwards D, Halliday H, Levene M, Thoresen M, Whitelaw A: The TOBY study: whole body hypothermia for the treatment of perinatal asphyxial encephalopathy - a randomised controlled trial. BMC Pediatr 2008;8:17.
19 Bednarek N, Mathur A, Inder T, Wilkinson J, Neil J, Shimony J: Impact of therapeutic hypothermia on MRI diffusion changes in neonatal encephalopathy. Neurology 2012;78: 1420-1427.

20 Boudes E, Tan X, Saint-Martin C, Shevell M, Wintermark P: MRI obtained during versus after hypothermia in asphyxiated newborns. Arch Dis Child Fetal Neonatal Ed 2015; 100:F238-F242.

21 Rutherford M, Ramenghi LA, Edwards AD, Brocklehurst $\mathrm{P}$, Halliday $\mathrm{H}$, Levene $\mathrm{M}$, Strohm B, Thoresen M, Whitelaw A, Azzopardi D: Assessment of brain tissue injury after moderate hypothermia in neonates with hypoxic-ischaemic encephalopathy: a nested substudy of a randomised controlled trial. Lancet Neurol 2010;9:39-45.

22 Harbert MJ, Tam EW, Glass HC, Bonifacio SL, Haeusslein LA, Barkovich AJ, Jeremy RJ, Rogers EE, Glidden DV, Ferriero DM: Hypothermia is correlated with seizure absence in perinatal stroke. J Child Neurol 2011;26: 1126-1130.

23 Lichter-Konecki U: Pilot study for hypothermia treatment in hyperammonemic encephalopathy in neonates and very young infants. 2007. http://www.clinicaltrials.gov/ct2/show/ NCT01624311.

24 Ilves P, Lintrop M, Metsvaht T, Vaher U, Talvik T: Cerebral blood-flow velocities in predicting outcome of asphyxiated newborn infants. Acta Paediatr 2004;93:523-528.

25 Eken P, Toet MC, Groenendaal F, de Vries LS: Predictive value of early neuroimaging, pulsed Doppler and neurophysiology in full term infants with hypoxic-ischaemic encephalopathy. Arch Dis Child Fetal Neonatal Ed 1995;73:F75-F80.

26 Kirimi E, Tuncer O, Atas B, Sakarya ME, Ceylan A: Clinical value of color Doppler ultrasonography measurements of full-term newborns with perinatal asphyxia and hypoxic ischemic encephalopathy in the first $12 \mathrm{~h}$ of life and long-term prognosis. Tohoku J Exp Med 2002;197:27-33.

27 Archer LN, Levene MI, Evans DH: Cerebral artery Doppler ultrasonography for prediction of outcome after perinatal asphyxia. Lancet 1986;2:1116-1118. 
28 Stark JE, Seibert JJ: Cerebral artery Doppler ultrasonography for prediction of outcome after perinatal asphyxia. J Ultrasound Med 1994;13:595-600.

29 Elstad M, Whitelaw A, Thoresen M: Cerebral resistance index is less predictive in hypothermic encephalopathic newborns. Acta Paediatr 2011;100:1344-1349.

30 Gerner GJ, Burton VJ, Poretti A: Transfontanellar duplex brain ultrasonography resistive indices as a prognostic tool in neonatal hypoxic-ischemic encephalopathy before and after treatment with therapeutic hypothermia. J Perinatol 2016;36:202-206.

31 Skranes JH, Elstad M, Thoresen M, Cowan FM, Stiris T, Fugelseth D: Hypothermia makes cerebral resistance index a poor prognostic tool in encephalopathic newborns. Neonatology 2014;106:17-23.

32 Liu Y, Harder DR, Lombard JH: Interaction of myogenic mechanisms and hypoxic dilation in rat middle cerebral arteries. Am J Physiol Heart Circ Physiol 2002;283:H2276$\mathrm{H} 2281$.

33 Haaland K, Karlsson B, Skovlund E, Thoresen M: Simultaneous measurements of cerebral circulation with electromagnetic flowmetry and Doppler ultrasound velocity in the newborn pig. Pediatr Res 1994;36:601-606.

34 Gunn AJ, Laptook AR, Robertson NJ, Barks JD, Thoresen M, Wassink G, Bennet L: Therapeutic hypothermia translates from ancient history in to practice. Pediatr Res 2017;81: 202-209.

35 Ferriero DM: Neonatal brain injury. N Engl J Med 2004;351:1985-1995.

36 Eken P, Jansen GH, Groenendaal F, Rademaker KJ, de Vries LS: Intracranial lesions in the fullterm infant with hypoxic ischaemic encephalopathy: ultrasound and autopsy correlation. Neuropediatrics 1994;25:301-307.

37 Pinto PS, Tekes A, Singhi S, Northington FJ, Parkinson C, Huisman TA: White-gray matter echogenicity ratio and resistive index: sonographic bedside markers of cerebral hypoxic-ischemic injury/edema? J Perinatol 2012; 32:448-453.

38 Nelson MD Jr, Tavare CJ, Petrus L, Kim P, Gilles FH: Changes in the size of the lateral ventricles in the normal-term newborn following vaginal delivery. Pediatr Radiol 2003; 33:831-835.

39 Myers RE: Four patterns of perinatal brain damage and their conditions of occurrence in primates. Adv Neurol 1975;10:223-234.

40 Azzarelli B, Caldemeyer KS, Phillips JP, DeMyer WE: Hypoxic-ischemic encephalopathy in areas of primary myelination: a neuroimaging and PET study. Pediatr Neurol 1996;14: 108-116.

41 Johnston MV, Hoon AH Jr: Possible mechanisms in infants for selective basal ganglia damage from asphyxia, kernicterus, or mitochondrial encephalopathies. J Child Neurol 2000;15:588-591.
42 Swarte R, Lequin M, Cherian P, Zecic A, van Goudoever J, Govaert P: Imaging patterns of brain injury in term-birth asphyxia. Acta Paediatr 2009;98:586-592.

43 Rutherford MA, Pennock JM, Dubowitz LM: Cranial ultrasound and magnetic resonance imaging in hypoxic-ischaemic encephalopathy: a comparison with outcome. Dev Med Child Neurol 1994;36:813-825.

44 Martinez-Biarge M, Diez-Sebastian J, Kapellou O, Gindner D, Allsop JM, Rutherford MA, Cowan FM: Predicting motor outcome and death in term hypoxic-ischemic encephalopathy. Neurology 2011;76:2055-2061.

45 Ashwal S, Majcher JS, Longo LD: Patterns of fetal lamb regional cerebral blood flow during and after prolonged hypoxia: studies during the posthypoxic recovery period. Am J Obstet Gynecol 1981;139:365-372.

46 Pasternak JF, Gorey MT: The syndrome of acute near-total intrauterine asphyxia in the term infant. Pediatr Neurol 1998;18:391-398.

47 Volpe JJ, Herscovitch P, Perlman JM, Kreusser KL, Raichle ME: Positron emission tomography in the asphyxiated term newborn: parasagittal impairment of cerebral blood flow. Ann Neurol 1985;17:287-296.

48 Yikilmaz A, Taylor GA: Cranial sonography in term and near-term infants. Pediatr Radiol 2008;38:605-616, quiz 718-609.

49 Connolly DJ, Widjaja E, Griffiths PD: Involvement of the anterior lobe of the cerebellar vermis in perinatal profound hypoxia. AJNR Am J Neuroradiol 2007;28:16-19.

50 Limperopoulos C, Robertson RL, Sullivan NR, Bassan H, du Plessis AJ: Cerebellar injury in term infants: clinical characteristics, magnetic resonance imaging findings, and outcome. Pediatr Neurol 2009;41:1-8.

51 Rollins N, Booth T, Morriss MC, Sanchez P, Heyne R, Chalak L: Predictive value of neonatal MRI showing no or minor degrees of brain injury after hypothermia. Pediatr Neurol 2014;50:447-451.

52 Tusor N, Wusthoff C, Smee N, Merchant N, Arichi T, Allsop JM, Cowan FM, Azzopardi D, Edwards AD, Counsell SJ: Prediction of neurodevelopmental outcome after hypoxicischemic encephalopathy treated with hypothermia by diffusion tensor imaging analyzed using tract-based spatial statistics. Pediatr Res 2012;72:63-69.

53 Nanba E, Eda I, Takashima S, Ohta S, Ohtani $\mathrm{K}$, Takeshita K: Intracranial hemorrhage in the full-term neonate and young infant: correlation of the location and outcome. Brain Dev 1984;6:435-443.

54 Wu YW, Hamrick SEG, Miller SP, Haward MF, Lai MC, Callen PW, Barkovich AJ, Ferriero DM: Intraventricular hemorrhage in term neonates caused by sinovenous thrombosis. Ann Neurol 2003;54:123-126.
55 Raju TN, Nelson KB, Ferriero D, Lynch JK: Ischemic perinatal stroke: summary of a workshop sponsored by the National Institute of Child Health and Human Development and the National Institute of Neurological Disorders and Stroke. Pediatrics 2007;120: 609-616.

56 Teixeira J, Zimmerman RA, Haselgrove JC, Bilaniuk LT, Hunter JV: Diffusion imaging in pediatric central nervous system infections. Neuroradiology 2001;43:1031-1039.

57 Westerlinck H, Meylaerts L, Van Hoestenberghe MR, Rossi A: Sulfite oxidase deficiency in a newborn. JBR-BTR 2014;97:113-114.

58 Chen LW, Tsai YS, Huang CC: Prenatal multicystic encephalopathy in isolated sulfite oxidase deficiency with a novel mutaion. Pediatr Neurol 2014;51:181-182.

59 Hoffmann C, Ben-Zeev B, Anikster Y, Nissenkorn A, Brand N, Kuint J, Kushnir T: Magnetic resonance imaging and magnetic resonance spectroscopy in isolated sulfite oxidase deficiency. J Child Neurol 2007;22:12141221.

60 Serrano M, Lizarraga I, Reiss J, Dias AP, Perez-Duenas B, Vilaseca MA, Artuch R, Campistol J, Garcia-Cazorla A: Cranial ultrasound and chronological changes in molybdenum cofactor deficiency. Pediatr Radiol 2007;37: 1043-1046

61 Luisiri A, Sotelo-Avila C, Silberstein MJ, Graviss ER: Sonography of the Zellweger syndrome. J Ultrasound Med 1988;7:169-173.

62 Mochel F, Grebille AG, Benachi A, Martinovic J, Razavi F, Rabier D, Simon I, Boddaert N, Brunelle F, Sonigo P: Contribution of fetal MR imaging in the prenatal diagnosis of Zellweger syndrome. AJNR Am I Neuroradiol 2006;27:333-336.

63 Paupe A, Bidat L, Sonigo P, Lenclen R, Molho M, Ville Y: Prenatal diagnosis of hypoplasia of the corpus callosum in association with nonketotic hyperglycinemia. Ultrasound Obstet Gynecol 2002;20:616-619.

64 McAdams RM, Richards TL: Detection of nonketotic hyperglycinemia in a neonate using proton magnetic resonance spectroscopy. Radiol Case Rep 2009;4:310.

65 Fariello G, Dionisi-Vici C, Orazi C, Malena S, Bartuli A, Schingo P, Carnevale E, Saponara I, Sabetta G: Cranial ultrasonography in maple syrup urine disease. AJNR Am J Neuroradiol 1996;17:311-315.

66 Wintermark P, Hansen A, Soul J, Labrecque M, Robertson RL, Warfield SK: Early versus late MRI in asphyxiated newborns treated with hypothermia. Arch Dis Child Fetal Neonatal Ed 2011;96:F36-F44.

67 Barkovich AJ, Miller SP, Bartha A, Newton N, Hamrick SE, Mukherjee P, Glenn OA, Xu D, Partridge JC, Ferriero DM, Vigneron DB: MR imaging, MR spectroscopy, and diffusion tensor imaging of sequential studies in neonates with encephalopathy. AJNR Am J Neuroradiol 2006;27:533-547. 
68 Epelman M, Daneman A, Kellenberger CJ, Aziz A, Konen O, Moineddin R, Whyte $\mathrm{H}$, Blaser S: Neonatal encephalopathy: a prospective comparison of head US and MRI. Pediatr Radiol 2010;40:1640-1650.

69 Twomey E, Twomey A, Ryan S, Murphy J, Donoghue VB: MR imaging of term infants with hypoxic-ischaemic encephalopathy as a predictor of neurodevelopmental outcome and late MRI appearances. Pediatr Radiol 2010;40:1526-1535.

70 De Vries LS, Van der Grond J, Van Haastert IC, Groenendaal F: Prediction of outcome in new-born infants with arterial ischaemic stroke using diffusion-weighted magnetic resonance imaging. Neuropediatrics 2005;36: $12-20$.

71 Massaro AN, Evangelou I, Fatemi A, Vezina G, McCarter R, Glass P, Limperopoulos C: White matter tract integrity and developmental outcome in newborn infants with hypoxicischemic encephalopathy treated with hypothermia. Dev Med Child Neurol 2015;57:441448.

72 Malik GK, Trivedi R, Gupta RK, Hasan KM, Hasan M, Gupta A, Pandey CM, Narayana PA: Serial quantitative diffusion tensor MRI of the term neonates with hypoxic-ischemic encephalopathy (HIE). Neuropediatrics 2006; 37:337-343.

73 Barkovich AJ, Westmark KD, Bedi HS, Partridge JC, Ferriero DM, Vigneron DB: Proton spectroscopy and diffusion imaging on the first day of life after perinatal asphyxia: preliminary report. AJNR Am J Neuroradiol 2001;22:1786-1794.

74 Lee YK, Penn A, Patel M, Pandit R, Song D, Ha BY: Hypothermia-treated neonates with hypoxic-ischemic encephalopathy: optimal timing of quantitative ADC measurement to predict disease severity. Neuroradiol J 2017; 30:28-35.
75 Boichot C, Walker PM, Durand C, Grimaldi M, Chapuis S, Gouyon JB, Brunotte F: Term neonate prognoses after perinatal asphyxia: contributions of MR imaging, MR spectroscopy, relaxation times, and apparent diffusion coefficients. Radiology 2006;239:839-848.

76 Alderliesten T, de Vries LS, Benders MJ, Koopman C, Groenendaal F: MR imaging and outcome of term neonates with perinatal asphyxia: value of diffusion-weighted MR imaging and (1)H MR spectroscopy. Radiology 2011;261:235-242.

77 Liauw L, van Wezel-Meijler G, Veen S, van Buchem MA, van der Grond J: Do apparent diffusion coefficient measurements predict outcome in children with neonatal hypoxicischemic encephalopathy? AJNR Am J Neuroradiol 2009;30:264-270

78 Groenendaal F, Veenhoven RH, van der Grond J, Jansen GH, Witkamp TD, de Vries LS: Cerebral lactate and N-acetyl-aspartate/ choline ratios in asphyxiated full-term neonates demonstrated in vivo using proton magnetic resonance spectroscopy. Pediatr Res 1994;35:148-151.

79 Shanmugalingam S, Thornton JS, Iwata O, Bainbridge A, O'Brien FE, Priest AN, Ordidge RJ, Cady EB, Wyatt JS, Robertson NJ: Comparative prognostic utilities of early quantitative magnetic resonance imaging spin-spin relaxometry and proton magnetic resonance spectroscopy in neonatal encephalopathy. $\mathrm{Pe}$ diatrics 2006;118:1467-1477.

80 Amess PN, Penrice J, Wylezinska M, Lorek A, Townsend J, Wyatt JS, Amiel-Tison C, Cady EB, Stewart A: Early brain proton magnetic resonance spectroscopy and neonatal neurology related to neurodevelopmental outcome at 1 year in term infants after presumed hypoxic-ischaemic brain injury. Dev Med Child Neurol 1999;41:436-445

81 Haller S, Zaharchuk G, Thomas DL, Lovblad KO, Barkhof F, Golay X: Arterial spin labeling perfusion of the brain: emerging clinical applications. Radiology 2016;281:337-356.
82 Petersen ET, Zimine I, Ho YC, Golay X: Noninvasive measurement of perfusion: a critical review of arterial spin labelling techniques. $\mathrm{Br}$ J Radiol 2006;79:688-701.

83 Wintermark P, Hansen A, Gregas MC, Soul J, Labrecque M, Robertson RL, Warfield SK: Brain perfusion in asphyxiated newborns treated with therapeutic hypothermia. AJNR Am J Neuroradiol 2011;32:2023-2029.

84 Massaro AN, Bouyssi-Kobar M, Chang T, Vezina LG, du Plessis AJ, Limperopoulos C: Brain perfusion in encephalopathic newborns after therapeutic hypothermia. AJNR Am J Neuroradiol 2013;34:1649-1655.

85 De Vis JB, Hendrikse J, Petersen ET, de Vries LS, van Bel F, Alderliesten T, Negro S, Groenendaal F, Benders MJ: Arterial spin-labelling perfusion MRI and outcome in neonates with hypoxic-ischemic encephalopathy. Eur Radiol 2015;25:113-121.

86 Hwang M, De Jong RM, Jr., Herman S, Boss R, Riggs B, Tekes-Brady A, Spevak M, Poretti A, Soares BP, Bailey CR, Dunn E, Shin SS, Shrot S, Huisman T: Novel contrast-enhanced ultrasound evaluation in neonatal hypoxic ischemic injury: clinical application and future directions. J Ultrasound Med 2017;36: 2379-2386

87 Cassia GS, Faingold R, Bernard C, Sant'Anna GM: Neonatal hypoxic-ischemic injury: sonography and dynamic color Doppler sonography perfusion of the brain and abdomen with pathologic correlation. AJR Am J Roentgenol 2012;199:W743-W752.

88 Bailey C, Huisman T, de Jong RM, Hwang M: Contrast-enhanced ultrasound and elastography imaging of the neonatal brain: a review. J Neuroimaging 2017;27:437-441.

89 Demene C, Pernot M, Biran V, Alison M, Fink M, Baud O, Tanter M: Ultrafast Doppler reveals the mapping of cerebral vascular resistivity in neonates. J Cereb Blood Flow Metab 2014;34:1009-1017. 